\title{
Investigation of factors associated with nausea and vomiting in pregnant women
}

\author{
๑Berrak Mızrak Şahin \\ Eskişehir Osmangazi University, Department of Nursing, Department of Obstetrics and Gynecology Nursing, Eskişehir, Turkey
}

Cite this article as: Mızrah Şahin B. Investigation of factors associated with nausea and vomiting in pregnant women. J Health Sci Med 2021; 4(4): 457-461.

\begin{abstract}
Aim: In the study, it was aimed to determine the factors that may be associated with nausea and vomiting in pregnant women.

Material and Method: The research was conducted between November 2020-February 2021. The sample consisted of 434 pregnant women. Included were primiparous and multiparous pregnant women aged 18 and older, at 6-16 weeks of gestation, able to read, write and understand the Turkish language. "Personal Information Form" and "PregnancyUnique Quantification of Emesis and Nausea-PUQE” were used as data collection tools. The data were collected by online questionnaire created in Google Forms. The data obtained from the study were analyzed using a statistical package program. A value of $\mathrm{p}<.05$ was accepted as the level of significance.

Results: $77.6 \%$ of the pregnant women had nausea and vomiting during pregnancy. The results of this study showed that pregnant women who were old age, unemployed, had nausea and vomiting in their previous pregnancies, did not use any vitamin supplements during their pregnancy, and whose fetüs was a girl were at high risk for nausea and vomiting during pregnancy.

Conclusion: Although nausea and vomiting during pregnancy are a natural physiological process, the findings obtained from this study provide more information about the potential factors associated with nausea and vomiting during pregnancy. Understanding potential risk factors associated with pregnancy can provide better guidance of pregnant women about nausea and vomiting and treatment options by healthcare professionals. Further studies are needed to examine lifestyle changes and psychological conditions during pregnancy, which are factors that can cause and increase nausea and vomiting.
\end{abstract}

Keywords: Pregnancy, nausea, vomiting, associated factors

\section{INTRODUCTION}

Nausea and vomiting are common experiences in pregnancy and occurring in $56-80 \%$ of all pregnancies during the first trimester. There is a wide range of severity of nausea and vomiting, from mild, occasional nausea to severe, persistent vomiting requiring hospitalization (1). Nausea and vomiting of pregnancy (NVP) is exacerbated and can cause maternal weight loss, electrolyte imbalance, and dehydration. This condition, defined as hyperemesis gravidarum (HG), is one of the most common causes of hospitalization in pregnant women (2).

NVP symptoms usually begins between 4-6 weeks of pregnancy, and peaks between 7-12 weeks $(3,4)$ and usually resolves before the 16th week of pregnancy (5). NVP can also be defined as "morning sickness" due to the fact that it usually occurs in the morning (6).

Although the etiology of NVP remains unclear, it appears to be positively associated with serum levels of estrogen and human chorionic gonadotropin (hCG). In addition, different studies have reported that factors such as age, ethnicity, number of pregnancies (7), gastrointestinal problems (8), personality traits, depression (3) are associated with NVP. However, the data in the studies are not consistent (1-7). Treatment -of NVP depends on the severity of symptoms and accompanying complications. Although nonpharmacological medications, diet and lifestyle changes can be effective in mild nausea and vomiting, they are ineffective in more severe cases. Pharmacotherapy is required when non-pharmacological interventions are not effective $(1,9)$. 
NVP is a condition that has negative effects on the individual, family, social and work life of the woman. NVP prevents women from practicing self-care, decreases their strength and makes them highly sensitive (6). Recognizing and treating NVP in a timely manner can prevent NVP from progressing to HG. All women with symptoms related to NVP should be counseled about safe and effective treatments early in their pregnancy. The pathogenesis of NVP is poorly understood, and the etiology is likely to be multifactorial. Identifying NVP and associated factors prevents progression of NVP and can assist with monitor treatment (10). The aim of this study was to investigate the factors affecting the nausea and vomiting of pregnancy.

\section{MATERIAL AND METHOD}

Permission was obtained from the Non-Interventional Ethics Committee of Eskisehir Osmangazi University (Date: 16.10.2020, Decision No: 08). All procedures were carried out in accordance with the ethical rules and the principles of the Declaration of Helsinki.

\section{Study Design and Sample}

A cross-sectional study was conducted from November 2020-February 2021. The sample consisted of 434 pregnant women. Included were primiparous and multiparous pregnant women aged 18 and older, at 6-16 weeks of gestation, able to read, write and understand the Turkish language. Diabetic disease, hyperthyroidism, heart disease, multiple pregnancy, molar pregnancy, kidney disease and gastrointestinal problems that could cause NVP were excluded from the study. These diseases were questioned according to medical diagnosis.

\section{Data Collection}

The data were collected with "Personal Information Form" and "Pregnancy-Unique Quantification of Emesis and Nausea-PUQE".

\section{Personal Information Form}

There were 24 questions in the Personal Information Form. The form was developed by the researcher to determine the socio-demographic characteristics of women, obstetric properties and symptoms related to NVP.

\section{Pregnancy-Unique Quantification of Emesis and Nausea-PUQE}

The Pregnancy-Unique Quantification of Emesis and Nausea-PUQE modified from the Rhodes scoring system (11) and based on the 3 items that included the number of daily vomiting episodes (for how long have you felt nauseated or sick to your stomach?), the length of nausea per day in hours (how many times do you vomit or throw up?), and the number of retching episodes (how many times have you had retching or dry heaves without bringing anything up?). Responses were then grouped into 5 different categories that were scored from 1 to 5 according to the severity of the symptom. Symptoms include last 24 hours (12). The scale was adapted to Turkish by Sucu et al (2009). In the PUQE test score between 3-6 points was defined as mild NVP, 7-12 points as moderate NVP and 13-15 points as severe NVP (13).

\section{Data Collection}

Data were collected via an online questionnaire reated in Google Forms. The form was shared in groups on Instagram and Facebook in which pregnant women participated extensively. The page administrators who created the groups were contacted and it was provided that the questionnaire was shared in groups at regular intervals. Before the web-based questionnaire, pregnant women approved the consent form that they agreed to participate in the study. The aim of the study and they can withdraw from the study at any time were explained in the consent form The pregnant women were asked whether they were diagnosed with diabetes, hyperthyroidism, heart disease, multiple pregnancy, molar pregnancy, kidney disease and gastrointestinal problems that may cause NVP and those with one of these diseases were excluded from the study.

\section{Statistical Analysis}

Descriptive statistics results of the sample are given as mean and standard deviation. Whether there is a difference in terms of socio-demographic, obstetric and other complaints in pregnant women with and without nausea-vomiting was evaluated with chi-square analysis for non-continuous variables.

The relationship between PUQE test scores of pregnant women with and without nausea-vomiting and some discontinuous control variables were analyzed with Kruskal-wallis on the number of groups $(>2)$. The significance level was considered $\mathrm{p}<.05$.

\section{RESULTS}

The socio-demographic and obstetric characteristics of the pregnant women are given in Table 1. The mean age of the participants $27.77 \pm 4.21,79.3 \%$ are university graduates. A total of $41.5 \%$ are between $6-12$ weeks and $58.5 \%$ are between 13-16 weeks of pregnancy.

$77.6 \%$ of the pregnant women had NVP. $39.2 \%$ of them used drug due to NVP. $21 \%$ of multiparous pregnant women experienced NVP in their previous pregnancies (Table 2).

The distribution of the average PUQE score of pregnant women classified as mild, moderate and severe NVP is given in Table 3. Half of pregnant women have moderate NVP (59.1\%). 


\begin{tabular}{|c|c|c|}
\hline $\begin{array}{l}\text { Socio-demographic and } \\
\text { obstetric characteristics }\end{array}$ & Mean & SD \\
\hline \multirow[t]{2}{*}{ Age } & 27.77 & 4.21 \\
\hline & $\mathbf{n}$ & $\%$ \\
\hline \multicolumn{3}{|l|}{ Education status } \\
\hline Primary education & 6 & 1.4 \\
\hline High school & 84 & 19.4 \\
\hline University & 384 & 79.3 \\
\hline \multicolumn{3}{|l|}{ Working status } \\
\hline Working & 176 & 40.6 \\
\hline Not working & 258 & 59.4 \\
\hline \multicolumn{3}{|l|}{ Number of pregnancies } \\
\hline Primiparous & 299 & 68.9 \\
\hline Multiparous & 135 & 31.1 \\
\hline \multicolumn{3}{|l|}{ Pregnancy week } \\
\hline $6-12$ & 180 & 41.5 \\
\hline $13-16$ & 254 & 58.5 \\
\hline \multicolumn{3}{|l|}{ Gender of fetus } \\
\hline Female & 112 & 25.8 \\
\hline Male & 102 & 23.5 \\
\hline Unknown & 220 & 50.7 \\
\hline
\end{tabular}

The relationship between the PUQE mean scores of the pregnant women and some socio-demographic, obstetric, and NVP related characteristics were examined (Table 4). As the age decreased, the severity of the NVP increased (KW=9.524, $\mathrm{p}=.023$ ). $24.4 \%$ of working mothers did not have NVP, while this rate was $20.9 \%$ for non-working mothers. NVP rate in non-working mothers were higher than in working mothers $(\mathrm{X} 2=702.140, \mathrm{p}=<.001)$. Participants who smoke during pregnancy had less NVP than non-smokers $(\mathrm{X} 2=13.920, \mathrm{p}=.034)$. Women who experienced NVP in their previous pregnancy had severe NVP in this pregnancy $(\mathrm{X} 2=47.630, \mathrm{p}=<.001)$. The

\begin{tabular}{|c|c|c|}
\hline $\begin{array}{l}\text { The characteristics of nausea and } \\
\text { vomiting during pregnancy }\end{array}$ & $\mathbf{n}$ & $\%$ \\
\hline \multicolumn{3}{|c|}{ Experiencing nausea and vomiting during pregnancy } \\
\hline Yes & 337 & 77.6 \\
\hline No & 97 & 22.4 \\
\hline \multicolumn{3}{|c|}{ Experiencing nausea and vomiting in previous pregnancies } \\
\hline Yes & 91 & 21.0 \\
\hline No & 44 & 10.1 \\
\hline \multicolumn{3}{|c|}{ Having sensitivity to smell during pregnancy } \\
\hline Yes & 396 & 91.2 \\
\hline No & 38 & 8.8 \\
\hline \multicolumn{3}{|l|}{ Drug use due to nausea and vomiting* } \\
\hline Yes & 132 & 39.2 \\
\hline No & 205 & 60.8 \\
\hline
\end{tabular}

\begin{tabular}{|lcc|}
\hline \multicolumn{3}{|l}{ Table 3. Distribution of the mean PUQE score of pregnant women } \\
\hline PUQE Classification & $\mathbf{n}$ & $\%$ \\
\hline Mild NVP & 120 & 35.6 \\
Moderate NVP & 199 & 59.1 \\
Severe NVP & 18 & 5.3 \\
PUQE Total score (Mean. \pm SD) & \multicolumn{2}{|c|}{$7.36 \pm 2.66$} \\
\hline
\end{tabular}

presence and severity of NVP decreased in those who used vitamins during pregnancy compared to those who did not use vitamins (X2=10.346, $\mathrm{p}=.016)$. Since the fetal gender is determined in the following weeks and the severity of NVP usually decreases in the following weeks, the effect of the fetal gender on the NVP had been evaluated according to whether the pregnant woman had NVP or not. Pregnant women with a female fetus (82.1\%) had a higher rate of NVP compared to pregnant women with a male fetus $(67.6 \%)(\mathrm{X} 2=6.020, \mathrm{p}=.014)$.

\begin{tabular}{|c|c|c|c|c|c|}
\hline \multirow{2}{*}{ Some characteristic } & \multirow[b]{2}{*}{ None } & \multicolumn{2}{|c|}{ Nausea-Vomiting } & \multirow[b]{2}{*}{ Severe } & \multirow[t]{2}{*}{ Statistical analysis } \\
\hline & & Mild & Moderate & & \\
\hline Age $($ Mean \pm SD) & $28.91 \pm 4.26$ & $28.55 \pm 4.63$ & $27.47 \pm 4.39$ & $27.29 \pm 3.67$ & $\begin{array}{c}\mathrm{KW}=9.524 \\
\mathrm{p}=.023^{*}\end{array}$ \\
\hline \multicolumn{6}{|l|}{ Education status, n (\%) } \\
\hline Primary education & $0(0.0)$ & $4(66.7)$ & $2(33.3)$ & $0(0.0)$ & \multirow{3}{*}{$\begin{array}{l}X^{2}=6.892 \\
p=.311^{* *}\end{array}$} \\
\hline High school & $15(17.9)$ & $26(31.0)$ & $39(46.4)$ & $4(4.8)$ & \\
\hline University & $82(23.8)$ & $90(26.2)$ & $158(45.9)$ & $14(4.1)$ & \\
\hline \multicolumn{6}{|l|}{ Working status, n (\%) } \\
\hline Working & $43(24.4)$ & $69(39.2)$ & $58(33.0)$ & $6(6.4)$ & \multirow{2}{*}{$\begin{aligned} \mathrm{X}^{2} & =702.140 \\
\mathrm{p} & =<.001^{* * *}\end{aligned}$} \\
\hline Not working & $54(20.9)$ & $51(19.8)$ & $141(54.7)$ & $12(4.7)$ & \\
\hline \multicolumn{6}{|l|}{ Number of pregnancies, $\mathbf{n}(\%)$} \\
\hline Primipar & $69(23.1)$ & $84(28.1)$ & $138(46.2)$ & $8(2.7)$ & \multirow{2}{*}{$\begin{array}{l}\mathrm{X}^{2}=5.336 \\
\mathrm{p}=.149^{* * *}\end{array}$} \\
\hline Multipar & $28(20.7)$ & $36(26.7)$ & $61(45.2)$ & $10(7.4)$ & \\
\hline \multicolumn{6}{|l|}{ Smoking during pregnancy, $\mathbf{n}(\%)$} \\
\hline Smoking & $9(42.9)$ & $2(9.5)$ & $10(47.6)$ & $0(0.0)$ & \multirow{3}{*}{$\begin{array}{c}\mathrm{X}^{2}=13.920 \\
\mathrm{p}=.034^{\star \star}\end{array}$} \\
\hline Not smoking & $84(22.2)$ & $112(29.6)$ & $167(44.1)$ & $16(4.2)$ & \\
\hline Used before pregnancy, not during pregnancy & $4(11.8)$ & $6(17.6)$ & $22(64.7)$ & $2(5.9)$ & \\
\hline \multicolumn{6}{|c|}{ Presence of nausea and vomiting in previous pregnancies, $\mathbf{n}(\%)$} \\
\hline Yes & $4(4.4)$ & $27(29.7)$ & $50(54.9)$ & $10(11.0)$ & \multirow{2}{*}{$\begin{array}{l}\mathrm{X}^{2}=47.630 \\
\mathrm{p}=<.001^{* * *}\end{array}$} \\
\hline No & $24(54.5)$ & $9(20.5)$ & $11(25.0)$ & $0(0.0)$ & \\
\hline \multicolumn{6}{|l|}{ Using a multivitamin during pregnancy } \\
\hline Yes & $85(25.4)$ & $94(28.1)$ & $143(42.8)$ & $12(3.6)$ & \multirow{2}{*}{$\begin{aligned} \mathrm{X}^{2} & =10.346 \\
\mathrm{p} & =.016^{\star * *}\end{aligned}$} \\
\hline \multirow[t]{2}{*}{ No } & $12(12.0)$ & $26(26.0)$ & $56(56.0)$ & $6(6.0)$ & \\
\hline & \multicolumn{2}{|c|}{ Yes } & \multicolumn{2}{|c|}{ No } & \\
\hline \multicolumn{6}{|l|}{ Fetus gender, $\mathbf{n}(\%)$} \\
\hline Female & \multirow{2}{*}{\multicolumn{2}{|c|}{$\begin{array}{l}92(82.1) \\
69(67.6)\end{array}$}} & \multirow{2}{*}{\multicolumn{2}{|c|}{$\begin{array}{l}20(17.9) \\
33(32.4)\end{array}$}} & \multirow{2}{*}{$\begin{array}{c}\mathrm{X}^{2}=6.020 \\
\mathrm{p}=.014^{\star \star \star \star *}\end{array}$} \\
\hline Male & & & & & \\
\hline
\end{tabular}




\section{DISCUSSION}

In our study, $77.6 \%$ of the pregnant women stated that they had NVP complaints. While this rate is similar to the results of some studies indicating NVP rates in the literatüre $(2,14,15)$, it was found higher than from some $(16,17)$. In our study and some studies showing a higher incidence of NVP, the NVP complaints of women were questioned in the early weeks, this provided better detection of early pregnancy conditions.

In this study older women were associated with mild NVP; this result is consistent with previous knowledge that increased age affects NVP. $(18,19)$.

The literature on the relationship between NVP and parity is uncertain: both primiparity $(20,21)$ and multiparity $(17,18,22)$ have been associated with NVP. Similar to our study, in studies that found a relationship between NVP and multiparity have shown that women who had NVP in their previous pregnancy have an increased risk of NVP in their subsequent pregnancies $(17,18,22)$. NVP tends to recur in subsequent pregnancies. Therefore, the absence of a history of NVP in previous pregnancies makes the diagnosis less likely (23).

Compared with working women, non-working women were at increased risk of NVP. The finding of our study are consistent with some studies which were identified non-working as a risk factor of NVP $(16,17)$. However, it remains unclear whether employment status is a true risk factor for NVP. Because women may stop working due to symptoms and may choose not to work pregnancy complications and the need to care for other children (16).

Due to the negative effect of smoking on the placenta during pregnancy, some data have been revealed that the placental volume remains small and therefore NVP complaint may decrease due to the decrease in hCG and estrogen hormone levels secreted (24). Our study and some study results in the literature showed that NVP decreased in pregnant women who smoke compared to non-smokers $(9,24)$.

In our study, vitamins were associated with a decreased risk for NVP. In addition, NVP severity decreases in pregnant women who have NVP and use vitamins. An association between vitamin supplementation and prevention of NVP has previously been described. However, no information was given about the pathogenesis of this relationship (9). One of the possible etiology of NVP is shown as vitamin B6 deficiency. The effect of vitamin B6 on nausea and vomiting is generally explained by the fact that vitamin B6 acts as a coenzyme in the reactivity of the amino acid lysine. It is explained by the fact that lysine reactivity reduces nausea and vomiting caused by increased estrogen levels in pregnant women (25). It is thought that NVP may decrease in these pregnant women due to vitamin B6, which may be in the content of the vitamins used by the participants.

As a social belief around the world, it is thought that the presence and intensity of NVP can be predictive of fetal gender. According to this belief, if a pregnant woman does not experience frequent NVP, she will probably give birth to a boy, and if she experiences intense NVP, she will give birth to a girl (21). In our study, it was determined that pregnant women with female fetus had a higher rate of NVP compared to pregnant women with male fetus. In a retrospective study conducted with 9,980 women giving birth in the United Kingdom, it was found that the incidence of hyperemesis gravidarum (HG) was higher in pregnant women whose babies were female than those whose babies were male (26). The pathogenesis of the relationship between NVP and fetüs gender is not fully known. However, the effect of hCG, an endocrine factor that can play an important role in NVP and mediate the effect of fetal gender on NVP, has been shown in some studies. hCG production may differ in terms of gender due to different placental gene expression (27), and chromosome-based sex differences in placenta can activate the pathways that lead to NVP (21).

\section{Limitations}

In the study, effect of nutritional habits and psychological factors on the NVP has not been evaluated.

PUQE test evaluates nausea and vomiting in the last 24 hours. Nausea and vomiting are evaluated together in the scale, but these symptoms may respond differently to pharmacologic and nonpharmacologic treatment. NVP symptoms usually begins between 4-6 weeks of pregnancy and resolves before the 16th week of pregnancy. Therefore, pregnant women at different weeks of gestation were included, but this wide range of gestational weeks may lead to different results.

\section{CONCLUSION}

In our study, it was found that compared to some previous studies, a higher prevalence of NVP and pregnant women were at higher risk for NVP due to some characteristics. The results of this study showed that pregnant women who were old age, unemployed, had NVP in their previous pregnancies, did not use any vitamin supplements during their pregnancy, and whose fetüs was a girl were at high risk for NVP. Although NVP is a usual physiological process, the findings obtained from this study provide more detailed 
information about the potential factors associated with NVP. Understanding potential risk factors associated with pregnancy can provide better guidance of pregnant women about NVP and treatment options by healthcare professionals. Further studies are needed to examine lifestyle changes and psychological conditions during pregnancy, which are factors that can cause and increase NVP.

\section{ETHICAL DECLARATIONS}

Ethics Committee Approval: Permission was obtained from the Non-Interventional Ethics Committee of Eskisehir Osmangazi University (Date: 16.10.2020, Decision No: 08).

Informed Consent: Written informed consent was obtained from all participants who participated in this study.

Conflict of Interest Statement: The author have no conflicts of interest to declare.

Financial Disclosure: The author declare that this study has received no financial support.

Author Contributions: All of the authors declare that they all participated in the design and the conduct of the study, and in the analysis of the study data. All authors have approved the final version.

\section{REFERENCES}

1. Tan A, Lowe S, Henry A. Nausea and vomiting of pregnancy: Effects on quality of life and day-to-day function. Aust N Z J Obstet Gynaecol 2018; 58: 278-90.

2. Chan RL, Olshan AF, Savitz DA, et al. Maternal influences on nausea and vomiting in early pregnancy. Matern Child Health J 2011; 15: 122-7.

3. Bahadırlı A, Sönmez MB, Memiş ÇÖ, et al. The association of temperament with nausea and vomiting during early pregnancy. J Obstet Gynaecol 2019; 39: 969-74.

4. Lacasse A, Rey E, Ferreira E, Morin C, Berard A. Nausea and vomiting of pregnancy: what about quality of life?. BJOG 2008; 115: 1484-93.

5. Büyükkurt S, Demir SC, Özgünen FT, Evrüke İC, Kadayıfcı O, Güzel AB. Evaluation of the patient with nausea and vomiting during pregnancy and treatment options. Turkiye Klinikleri J Gynecol Obst 2008; 18: 106-16.

6. Timur S, Kizılırmak A. Frequency of nausea-vomiting in early pregnancy and determination of the related factors. TAF Prev Med Bull 2011; 10: 281-86.

7. Coronado PJ, Fasero M, Álvarez-Sánchez Á, Rey E. Prevalence and persistence of nausea and vomiting along the pregnancy. Rev Esp Enferm Dig 2014; 106: 318-24.

8. Koch KL. Gastrointestinal factors in nausea and vomiting of pregnancy. Am J Obstet Gynecol 2002; 186: 198-203.

9. Källén B, Lundberg G, Åberg A. Relationship between vitamin use, smoking, and nausea and vomiting of pregnancy. Acta Obstet Gynecol Scand 2003; 82: 916-20.

10. Campbell K, Rowe H, Azzam H, Lane CA. The management of nausea and vomiting of pregnancy. J Obstet Gynaecol Can 2016; 38: 1127-37.
11. Rhodes VA, Watson PM, Johnson MH. Development of reliable and valid measures of nausea and vomiting. Cancer Nurs. 1984; 7: $33-42$.

12. Koren G, Boskovic R, Hard M, Maltepe C, Navioz Y, Einarson A. Motherisk-PUQE (pregnancy-unique quantification of emesis and nausea) scoring system for nausea and vomiting of pregnancy. Am J Obstet Gynecol 2002; 186: 228-31.

13. Sucu M, Büyükkurt S, Evrüke İ, Demir S, Özgünen F, Kadayıfçı O. The role of PUQE (Pregnancy-Unique Quantification of Emesis and Nausea) in evaluation of the indications for inpatient therapy in pregnants with nausea and vomiting. Turkiye Klinikleri J Gynecol Obst 2009; 19: 317-21.

14.Lagiou P, Tamimi R, Mucci LA, Trichopoulos D, Adami HO, Hsieh CC. Nausea and vomiting in pregnancy in relation to prolactin, estrogens, and progesterone: a prospective study. Obstet Gynecol 2003; 101: 639-44.

15.Lacroix R, Eason E, Melzack R. Nausea and vomiting during pregnancy: a prospective study of its frequency, intensity, and patterns of change. Am J Obstet Gynecol 2000; 182: 931-7.

16.Zhang H, Wu S, Feng J, Liu Z. Risk factors of prolonged nausea and vomiting during pregnancy. Risk Manag Healthc Policy 2020; 13: 2645-54.

17.Louik C, Hernandez-Diaz S, Werler MM, Mitchell AA. Nausea and vomiting in pregnancy: maternal characteristics and risk factors. Paediatr Perinat Epidemiol 2006; 20: 270-8.

18. Dekkers GW, Broeren MA, Truijens SE, Kop WJ, Pop VJ. Hormonal and psychological factors in nausea and vomiting during pregnancy. Psychol Med 2020; 50: 229-36.

19. Jueckstock J, Kaestner R, Mylonas I. Managing hyperemesis gravidarum: a multimodal challenge. BMC Med 2010; 8: 1-12

20. Lee NM, Saha S. Nausea and vomiting of pregnancy. Gastroenterol Clin North Am 2011; 40: 309-34.

21. Young NR, La Rosa M, Mehr SA, Krasnow MM. Does greater morning sickness predict carrying a girl? Analysis of nausea and vomiting during pregnancy from retrospective report. Arch Gynecol Obstet 2020: 1-6.

22. Chortatos A, Haugen M, Iversen P, Vikanes Å, Magnus P, Veierød $M$. Nausea and vomiting in pregnancy: associations with maternal gestational diet and lifestyle factors in the Norwegian mother and child cohort study. BJOG 2013; 120: 1642-53.

23. Jarvis S, Nelson-Piercy C. Management of nausea and vomiting in pregnancy. BMJ 2011;342.

24. Weigel MM, Weigel RM. The association of reproductive history, demographic factors, and alcohol and tobacco consumption with the risk of developing nausea and vomiting in early pregnancy. Am J Epidemiol. 1988; 127: 562-70.

25. Wibowo N, Purwosunu Y, Sekizawa A, Farina A, Tambunan V, Bardosono S. Vitamin B6 supplementation in pregnant women with nausea and vomiting. Int J Gynaecol Obstet 2012; 116: 20610 .

26. Rashid M, Rashid M, Malik F, Herath R. Hyperemesis gravidarum and fetal gender: a retrospective study. J Obstet Gynaecol 2012; 32: 475-78.

27.Cvitic S, Longtine MS, Hackl $\mathrm{H}$, et al. The human placental sexome differs between trophoblast epithelium and villous vessel endothelium. PloS one 2013; 8: e79233. 